\section{(2) OPEN ACCESS}

\title{
Acceptability of a 'treat to target' approach in inflammatory bowel disease to patients in clinical remission
}

\author{
Christian Selinger (D) , 1,2 Jenelyn Carbonell, ${ }^{1}$ John Kane (D) , \\ Mandour Omer, ${ }^{1}$ Alexander Charles Ford (iD) 1,2
}

\begin{abstract}
'Leeds Gastroenterology Institute, Leeds Teaching Hospitals NHS Trust, Leeds, UK ${ }^{2}$ Leeds Institute of Medical Research at St James's Hopsital, University of Leeds, Leeds, UK
\end{abstract}

\section{Correspondence to} Dr Christian Selinger, Leeds Gastroenterology Institute, Leeds Teaching Hospitals NHS Trust, Leeds LS9 7TF, UK; christian. selinger@web.de

Received 18 November 2019 Revised 8 January 2020 Accepted 11 January 2020 Published Online First 24 January 2020

\section{SLinked}

- http://dx.doi.org/10.1136/ flgastro-2019-101372

\section{Check for updates}

(C) Author(s) (or their employer(s)) 2021. Re-use permitted under CC BY-NC. No commercial reuse. See rights and permissions. Published by BMJ.

To cite: Selinger $C$ Carbonell J, Kane J, et al. Frontline Gastroenterology 2021;12:30-38.

\begin{abstract}
Background A 'treat to target' approach aiming for remission of clinical symptoms and absence of mucosal inflammation has been proposed in inflammatory bowel disease (IBD). We aimed to establish whether patients with IBD in clinical remission find this approach acceptable.

Methods Patients in glucocorticosteroid-free clinical remission underwent a face-to-face structured, quantitative interview and rated the acceptability of treat to target on a 10-point Likert scale. We analysed factors associated with agreement to treat to target.

Results The cohort comprised 298 patients (144 Crohn's disease, 136 ulcerative colitis, 18 IBDunclassified). Elevated C-reactive protein was found in $24.4 \%$ and elevated faecal calprotectin in $17.7 \%$. Overall, $66.2 \%$ of patients rated a treat to target approach as acceptable (Likert scale $\geq 8$ ). Acceptable treatment aims for patients were avoidance of flare, hospitalisation, surgery and colorectal cancer. Using binary logistic regression analysis the following were not predictive of accepting a treat to target approach: age, diagnosis, disease phenotype, surgical history, disease duration, patient knowledge, adherence, anxiety, depression and patient-reported control of disease. Better adherence to current therapy was associated with accepting a treat to target approach $(B=0.16, p=0.039)$.
\end{abstract}

Conclusion In a cohort of patients in clinical remission, where this strategy is most relevant, two-thirds of patients agreed with treat to target. Patients with better current adherence were more likely to accept treat to target.

Patient education and counselling materials will need to be developed to convince a substantial minority of patients of the importance of treat to target.

\section{Significance of this study}

What is already known on this topic

- Occult inflammation in patients with inflammatory bowel disease (IBD) is associated with a higher risk of adverse disease course.

- In Crohn's disease clinical trials treat to target approaches have been associated with better clinical outcomes.

- Treatment adherence in IBD is often poor.

What this study adds

- Patient views on treat to target: $66 \%$ agree with this approach.

- One-third of patients remains unconvinced of a treat to target approach.

- There is an unmet need for patient on education on treat to target approaches.

How might it impact on clinical practice in the foreseeable future?

- Clinicians will need to consider how to provide sufficient patient education to explain the rationale and concept of treat to target approaches.

\section{INTRODUCTION}

Medical treatment for inflammatory bowel disease (IBD) has undergone a complete transformation over the last 25 years, due to the advent of newer biological and novel small molecule treatments. ${ }^{1}$ Patients benefit from anti-tumour necrosis factor (anti-TNF) agents, anti-integrin and anti-interleukin 12/23 (IL-12/23) drugs and the first small molecule has recently become available, with more in development. $^{2-5}$ Traditional treatment approaches were based on a step-up principle involving mesalazine (for ulcerative colitis (UC) only), to immunomodulators and then biological agents. ${ }^{6}$ However, this 
approach can lead to long delays in achieving remission, and subsequent poor quality of life or even development of IBD-related complications and surgery.

Traditionally the mainstay of therapy was to achieve clinical remission, or absence of symptoms, ideally in a glucocorticosteroid-free setting. This target is easily understood by patients, and glucocorticosteroid-free clinical remission is one of the main patient goals. ${ }^{7}$ However, a substantial proportion of patients in clinical remission have evidence of ongoing inflammation. ${ }^{8}$ Patients with such 'occult' inflammation may be at a higher risk of developing disease-related complications, including flares, hospitalisation and the need for surgery, while those achieving mucosal healing are at a much-reduced risk of complications. ${ }^{9-14}$ Recently, different treatment approaches have been proposed. These include a top-down approaches for Crohn's disease (CD) using combination therapy of immunomodulator and anti-TNF early in the disease course to avoid long-term complications. ${ }^{15}$ In addition approaches aiming for a more stringent target than clinical remission have been proposed. The Selecting Therapeutic Targets in IBD (STRIDE) consensus has defined mucosal healing targets for both UC and CD. ${ }^{16}$ Although mucosal healing is yet to become a universally agreed target for clinical care. A 'treat to target' approach where, instead of aiming for clinical remission, a treatment target such as mucosal healing is agreed with the patient has been proposed as a new standard of care. ${ }^{16}{ }^{17}$ Regular disease assessment would then occur to ensure therapy is escalated until clinical remission and mucosal healing is achieved. Two clinical trials have shown that a treat to target approach leads to better medium-term outcomes in CD. ${ }^{11} 18$

A recent systematic review has examined the evidence for a treat to target approach in UC. ${ }^{17}$ This has highlighted that questions regarding the best treatment targets incorporating clinical, endoscopic, histological and non-invasive measure of inflammation and how to measure them, remain. ${ }^{17}$ The review also confirmed that there are gaps in the current evidence base to justify widespread implementation of treat to target approaches. Importantly, it also underlined the importance of incorporating the patient's perspective into these new approaches. ${ }^{17}$ However, treatment in IBD is complicated by high rates of non-adherence to IBD-related medications by patients. ${ }^{19}{ }^{20}$ In light of the uncertainty surrounding the patient perspective of treat to target, we aimed to establish whether this approach is, in principle, acceptable to those in whom this strategy is most relevant; patients with IBD who are in clinical remission.

\section{METHODS}

\section{Population and setting}

Leeds Teaching Hospitals NHS Trust provides secondary and tertiary care to approximately 3000 patients with IBD in dedicated clinics provided by gastroenterologists with a subspecialty interest in IBD. The study population includes an unselected cohort of all patients with IBD in the hospital catchment area. In accordance with current guidance from the National Institute of Health and Care Excellence, choice of therapy is largely based on the aim of achieving glucocorticosteroid-free clinical remission. ${ }^{4}$ At the time this study was conducted, this patient cohort was therefore naïve to the concept of treat to target. Furthermore, the concept of treat to target was not previously discussed with patients under the Leeds IBD service. For the purpose of this study we defined the concept of treat to target as aiming for the absence of mucosal inflammation.

\section{Recruitment}

Consecutive patients identified as having achieved clinical remission, as assessed by physician global assessment, were identified. After written informed consent was obtained, participants underwent a 30-min face-toface quantitative interview with a single research nurse using an interviewer administered questionnaire, the details of which are outlined below. The study nurse introduced the hypothetical study scenario that a stool test, blood test, imaging or an endoscopy had showed abnormal levels of inflammation. The study nurse then explained to the patient that this means a higher risk of disease progression (including flares, hospitalisation, surgery or the risk of developing colorectal cancer), to the patient. For this verbal explanations were used but not visual or written materials were offered to the participant. The patient was then instructed to base all responses on this scenario. It was made clear that this was a hypothetical research exercise, rather than a conversation based on the results of an individual patient's tests. We did not propose any specific treatments to the patient but assessed their general attitude towards the treat to target concept.

\section{Inclusion criteria}

All adults aged 18 years and over with a confirmed diagnosis of IBD, who were judged to be in clinical glucocorticosteroid-free remission by global physician assessment were eligible for the study. Patients did not have to be taking maintenance therapy for their IBD to be eligible for inclusion. Study eligibility included patients with normal or elevated inflammation markers, normal imaging or radiological evidence of active disease and normal endoscopic investigations or endoscopic evidence of active disease. Patients were not required to have undergone any recent imaging or endoscopy as part of the study.

\section{Exclusion criteria}

Patients who lacked the capacity to consent and patients unable to communicate in English were excluded. Those patients with a current acute flare of their IBD or symptoms attributed to ongoing disease activity were 
also excluded from participation. Glucocorticosteroid use, including budesonide, was not permitted within 2 weeks prior to recruitment. Patients with UC, who had a colectomy, were not eligible for participation.

\section{Data collection}

Data regarding the medical, social and disease-specific history (demographics, diagnosis and phenotype, previous surgery, previous hospitalisations and latest blood, stool, radiology or endoscopy results) were collected from the hospital electronic and paper records. Medication history was recorded from the electronic hospital records. As the study recruited from 2015 to early 2017 anti-IL-12/23 therapy was not locally available for most of the study period and use of anti-integrins was infrequent during the study period and therefore not captured. Participants were asked to provide a stool sample at baseline for faecal calprotectin (FC) measurement. FC was deemed elevated at readings $\geq 250 \mu \mathrm{g} / \mathrm{g}$ and $\mathrm{C}$-reactive protein (CRP) was deemed elevated at readings $\geq 5 \mathrm{mg} / \mathrm{L}$.

\section{Questionnaires}

We used five questionnaires and, where available, fully validated instruments were used. All participants were judged to be in clinical remission by the responsible physician, but to ascertain patients' perceptions all participants were asked to report their perception of the state of their IBD using a 10-point Likert scales (1-very poor to 10 -excellent) separately for current disease state and disease state over the last 3 years. We used the Hospital Anxiety and Depression Scale (HADS) to assess for anxiety and depression, ${ }^{21}$ the Short IBD Quality of Life Questionnaire to assess quality of life ${ }^{22}$ and the Medication Adherence Report Scale (MARS) to assess adherence to current maintenance medication. ${ }^{23}{ }^{24}$ Disease-related patient knowledge was measured with the short IBD knowledge questionnaire. ${ }^{25}$ Patients were asked to rate how acceptable a treat to target approach was to them on 10-point Likert scales. In accordance with adherence studies (cut-off usually $80 \%$ ) we determined that a Likert scale rating of $\geq 8$ represented acceptance of a treat to target approach. ${ }^{26}$ We also asked patients about their views on specific therapeutic goals. Participants were asked whether avoiding complications including a disease flare during the next year, an IBD-related hospitalisation during the next year, the need for surgery during the next 5 years or the development of colorectal cancer during the next 20 years were desirable treatment goals. For each goal we asked participants what level of risk of the complication occurring (10\%-100\%, presented as a 10-point Likert scale) would be required in order for them to deem this an acceptable treatment goal. Participants were then asked what level of benefit they would expect from medical therapy in order to avoid the disease complication (presented as a relative risk reduction (RRR) 10\%, 25\%, 50\%, 90\%).

\section{Primary outcome}

The primary outcome was defined as the percentage of patients accepting treat to target, defined by a Likert scale score of $\geq 8$.

\section{Secondary outcomes}

Secondary outcomes included factors influencing the choice for or against a treat to target approach, and an assessment of treatment goals for patients, including the level of risk of an adverse event occurring that would be required to accept treatment, as well as the level of benefit expected by patients.

\section{Sample size and recruitment plan}

As no estimates for the primary outcome existed, no formal power calculation was performed. The study target was 300-400 patients, representing $10 \%$ of the IBD clinic cohort, which was deemed sufficient to gain data that were representative of the entire clinic cohort.

\section{Statistical analysis plan}

Data analysis was performed using SPSS V.25.0. Patient demographics, IBD phenotype and treatment history were reported using descriptive statistics. Continuous variables were compared using an independent t-test for normally distributed data and a Mann-Whitney $\mathrm{U}$ test for non-normally distributed data. Categorical variables were analysed using Pearson $\chi^{2}$ test. Associations were tested using Spearman correlation. We considered all analysis yielding $\mathrm{p}$ values $<0.05$ to be statistically significant. To assess for independence of factors, categorical factors were analysed again as dichotomous variables (for medication ever vs never exposure; for disease type UC vs CD). All factors were entered into a binary logistic regression analysis model (using treat to target acceptance as the selection variable and all variates from table 3 as the covariates with enter method of analysis) to assess for independent factors associated with accepting a treat to target approach.

\section{RESULTS}

\section{Patient characteristics}

The cohort comprised 298 patients (145 males; 48.9\%) including 144 with CD (48.3\%), 136 with UC (45.6\%) and 18 with IBD-unclassified (IBD-U) (6.1\%). Median age was 46 years, and median disease duration 7 years (table 1). Current medications included mesalazine in $44.3 \%$, thiopurines in $30.5 \%$, biologicals in $26.1 \%$ and methotrexate in $3.2 \% .96$ patients $(32.2 \%)$ had never been exposed to immunosuppressive treatment. Abnormal HADS anxiety scores (defined as $\geq 11$ ) were present in $22.5 \%$ and abnormal depression scores in $11.4 \%$ (table 2). Non-adherence, defined as MARS $\leq 16$, occurred in $15.8 \%$, and the median knowledge score was 3 . 


\section{Table 1 Cohort composition}

\begin{tabular}{|c|c|c|}
\hline & $\mathrm{N}$ & Percentage \\
\hline \multicolumn{3}{|l|}{ Sex } \\
\hline Male & 145 & 48.70 \\
\hline Female & 153 & 51.30 \\
\hline Median age & 46 years & \\
\hline Median disease duration & 7 years & \\
\hline \multicolumn{3}{|l|}{ Diagnosis } \\
\hline$C D$ & 144 & 48.30 \\
\hline$U C$ & 136 & 45.60 \\
\hline IBD-U & 18 & 6 \\
\hline \multicolumn{3}{|l|}{ UC/IBD-U extent } \\
\hline E1 (proctitis) & 22 & 14.40 \\
\hline E2 (left-sided colitis) & 82 & 53.60 \\
\hline E3 (extensive colitis) & 49 & 32.00 \\
\hline Unknown & 1 & \\
\hline \multicolumn{3}{|l|}{ CD phenotype } \\
\hline A1 (<16 years at diagnosis) & 6 & 4.20 \\
\hline A2 (17-40 years) & 108 & 75.00 \\
\hline A3 (>40 years) & 30 & 20.80 \\
\hline L1 (ileal) & 47 & 32.90 \\
\hline L2 (colonic) & 37 & 25.90 \\
\hline L3 (ileo-colonic) & 59 & 41.20 \\
\hline L4 (upper Gl, isolated and/or modifier) & 13 & 9.00 \\
\hline L not known & 1 & \\
\hline B1 (inflammatory) & 69 & 47.90 \\
\hline B2 (structuring) & 41 & 28.50 \\
\hline B3 (penetrating) & 34 & 23.60 \\
\hline Perianal disease & 35 & 32.10 \\
\hline Previous IBD-related surgery & 70 & 23.50 \\
\hline \multicolumn{3}{|l|}{ Mesalazine } \\
\hline Previous & 95 & 31.90 \\
\hline Current & 132 & 44.30 \\
\hline \multicolumn{3}{|l|}{ Thiopurines } \\
\hline Previous & 97 & 32.60 \\
\hline Current & 91 & 30.50 \\
\hline \multicolumn{3}{|l|}{ Methotrexate } \\
\hline Previous & 10 & 3.40 \\
\hline Current & 8 & 2.70 \\
\hline \multicolumn{3}{|l|}{ First anti-TNF } \\
\hline Previous & 45 & 15.10 \\
\hline Current & 60 & 20.10 \\
\hline \multicolumn{3}{|l|}{ Second anti-TNF } \\
\hline Previous & 7 & 2.30 \\
\hline Current & 18 & 6.00 \\
\hline
\end{tabular}

$\mathrm{CD}$, Crohn's disease; IBD, inflammatory bowel disease; TNF, tumour necrosis factor; UC, ulcerative colitis.

\section{Symptoms and objective inflammation}

Patients self-rated their current symptomatic state (control) and the state (control) over the last 3 years of their IBD on 10 -point Likert scales ( 0 poor control, 10 excellent control). Subjectively, very good current control $(\geq 8)$ was reported by $60.9 \%$ and very good control $(\geq 8)$ over the last 3 years by $31.2 \%$. An
Table 2 Psychometric results and current medical state

\begin{tabular}{lrl}
\hline & N & Percentage \\
\hline HADS & & \\
\hline No anxiety (score 0-7) & 140 & 47.00 \\
\hline Mild anxiety (score 8-10) & 91 & 30.50 \\
\hline Definite abnormal anxiety (score $\geq 11)$ & 67 & 22.50 \\
\hline No anxiety (score 0-7) & 192 & 64.40 \\
\hline Mild depression (score $\geq 8)$ & 72 & 24.20 \\
\hline Definite abnormal depression (score $\geq 11)$ & 34 & 11.40 \\
\hline Medication adherence (MARS) & & \\
Adherent (score $>16)$ & 251 & 84.20 \\
\hline Non-adherent (score $\leq 16)$ & 47 & 15.80 \\
\hline Inflammation status & & \\
\hline Abnormal CRP $(>5 \mathrm{mg} / \mathrm{L})$ & 73 & 24.40 \\
Abnormal FC $(\geq 250 \mu \mathrm{g} / \mathrm{g})$ & 53 & 17.70 \\
\hline
\end{tabular}

CRP, C-reactive protein; FC, faecal calprotectin; HADS, Hospital Anxiety and Depression Scale; MARS, Medication Adherence Report Scale.

elevated CRP was found in 24.4\%, and an elevated FC in $17.7 \%$. Patient-reported current control of IBD correlated only weakly with FC (Pearson -0.169; $\mathrm{p}=0.004)$, but not with CRP (Pearson $-0.075 ; \mathrm{p}=0.2$ ). No correlation between CRP or FC and control over the last 3 years was found.

\section{Treat to target acceptance and associated factors}

Overall, $66.2 \%$ of patients rated a treat to target approach as acceptable (figure 1). We performed a sensitivity analysis on the primary outcome. By lowering the threshold for acceptance to $\geq 7$ 73\% would have been classed as accepting treat to target while increasing the threshold to $\geq 9$ would have classed $57.8 \%$ as accepting. There was no association between age, diagnosis, disease phenotype, surgical history, disease duration, patient knowledge, anxiety, depression or patient-reported state of disease, either current or over the last 3 years and acceptance of a treat to target approach (table 3). Patients on a second-line

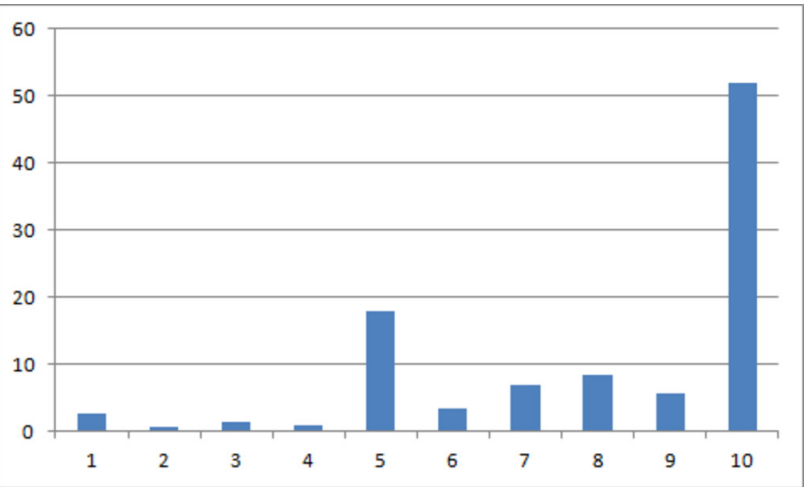

Figure 1 Percentage of patients rating the acceptability of treat to target on a 10-point Likert scale. A score of 1 indicates the lowest acceptability of treat to target whereas a score of 10 indicates the highest acceptability of treat to target. A score of 8 or greater represents acceptance of treat to target. 
Table 3 Factors associated with accepting treat to target approach

\begin{tabular}{|c|c|c|c|c|}
\hline & $\begin{array}{l}\text { Treat to target } \\
\text { not accepting }\end{array}$ & $\begin{array}{l}\text { Treat to target } \\
\text { accepting }\end{array}$ & Univariate analysis & Binary logistic regression \\
\hline \multicolumn{5}{|l|}{ Diagnosis (n) } \\
\hline$C D$ & 54 & 90 & & $B=-1.28$ \\
\hline UC & 38 & 98 & & \\
\hline IBD-U & 8 & 10 & $p=0.2$ & $p=0.021$ \\
\hline IBD-related surgery (n) & & & & $B=0.95$ \\
\hline Yes & 18 & 52 & & \\
\hline No & 82 & 146 & $p=0.2$ & $p=0.08$ \\
\hline \multicolumn{5}{|l|}{ Mesalazine treatment (n) } \\
\hline Never & 26 & 45 & & $B=-0.49$ \\
\hline Previous & 34 & 61 & & \\
\hline Current & 40 & 92 & $p=0.7$ & $p=0.3$ \\
\hline \multicolumn{5}{|l|}{ Thiopurine treatment (n) } \\
\hline Never & 38 & 72 & & $B=0.3$ \\
\hline Previous & 33 & 64 & & \\
\hline Current & 29 & 62 & $p=0.9$ & $p=0.5$ \\
\hline \multicolumn{5}{|l|}{ First-line anti-TNF treatment (n) } \\
\hline Never & 67 & 126 & & $B=-0.56$ \\
\hline Previous & 20 & 25 & & \\
\hline Current & 13 & 47 & $p=0.08$ & $p=0.3$ \\
\hline \multicolumn{5}{|l|}{ Second-line anti-TNF treatment (n) } \\
\hline Never & 84 & 186 & & $B=0.63$ \\
\hline Previous & 1 & 6 & & \\
\hline Current & 12 & 6 & $p=0.012$ & $p=0.4$ \\
\hline $\begin{array}{l}\text { Disease duration (median in years, not } \\
\text { normally distributed) }\end{array}$ & 7 & 8 & $p=0.4$ & $\begin{array}{l}B=-0.004 \\
p=0.9\end{array}$ \\
\hline Age (mean in years, normally distributed) & 44.7 & 48.7 & $p=0.07$ & $\begin{array}{l}B=-0.006 \\
p=0.7\end{array}$ \\
\hline $\begin{array}{l}\text { Patient knowledge (mean, normally } \\
\text { distributed) }\end{array}$ & 4 & 4 & $p=0.09$ & $\begin{array}{l}B=0.66 \\
p=0.5\end{array}$ \\
\hline $\begin{array}{l}\text { CRP (available for } 281 \text { patients, median, } \\
\text { not normally distributed) }\end{array}$ & 1 & 1 & $p=0.7$ & $\begin{array}{l}B=0.59 \\
p=0.1\end{array}$ \\
\hline $\begin{array}{l}\text { FC ( } 186 \text { samples returned, median, not } \\
\text { normally distributed) }\end{array}$ & 104 & 111 & $p=0.7$ & $\begin{array}{l}B=0 \\
p=0.4\end{array}$ \\
\hline $\begin{array}{l}\text { Patient-reported current disease control } \\
\text { (10-point Likert scale, median, not } \\
\text { normally distributed) }\end{array}$ & 9 & 8 & $p=0.6$ & $\begin{array}{l}B=0.13 \\
p=0.6\end{array}$ \\
\hline $\begin{array}{l}\text { Patient-reported 3-year disease control } \\
\text { (10-point Likert scale, median, not } \\
\text { normally distributed) }\end{array}$ & 7 & 7 & $p=0.6$ & $\begin{array}{l}B=0.04 \\
p=0.6\end{array}$ \\
\hline $\begin{array}{l}\text { HADS anxiety (median, not normally } \\
\text { distributed) }\end{array}$ & 8 & 7 & $p=0.2$ & $\begin{array}{l}B=-0.26 \\
p=0.8\end{array}$ \\
\hline $\begin{array}{l}\text { HADS depression (median, not normally } \\
\text { distributed) }\end{array}$ & 7 & 6 & $p=0.4$ & $\begin{array}{l}B=-0.13 \\
p=0.2\end{array}$ \\
\hline $\begin{array}{l}\text { Medication adherence (MARS, median, } \\
\text { not normally distributed) }\end{array}$ & 19 & 20 & $p=0.032$ & $\begin{array}{l}B=0.16 \\
p=0.039\end{array}$ \\
\hline $\begin{array}{l}\text { Quality of life (SIBDQ, median, not } \\
\text { normally distributed) }\end{array}$ & 54 & 56 & $p=0.4$ & $\begin{array}{l}B=-0.55 \\
p=0.1\end{array}$ \\
\hline
\end{tabular}

CD, Crohn's disease; FC, faecal calprotectin; HADS, Hospital Anxiety and Depression Scale; IBD, inflammatory bowel disease; MARS, Medication Adherence Report Scale; NB, where figures do not add up to 298 the relevant status was not known for some patients; SIBDQ, Short IBD Quality of Life Questionnaire; TNF, tumour necrosis factor; UC, ulcerative colitis.

anti-TNF were less likely to agree to a treat to target approach $(\mathrm{p}=0.012)$. Better self-reported medication adherence, as measured by MARS, was associated with accepting a treat to target approach (median 20 vs 19 for not accepting, $\mathrm{p}=0.023$ ). However, median adherence scores in both accepting and non-accepting 
groups were high (adherence is defined as MARS > 16). Binary logistic regression analysis revealed that only better adherence to medication was independently associated with accepting a treat to target approach $(\mathrm{B}=0.16, \mathrm{p}=0.039$; table 3$)$. We examined predictive factors separately for UC and CD: the only positive predictor of acceptability in UC was higher knowledge (4.03 vs 3.21, $\mathrm{p}=0.026$ ); while in $\mathrm{CD}$ second-line anti-TNF use (lower acceptance, $p=0.13$ ) and higher MARS adherence scores (higher acceptance, $p=0.011$ ) were associated with acceptance of treat to target.

\section{Treatment target acceptance and risk reduction}

Patients rated the acceptability of treatment aims, as well as the level of absolute risk and the level of benefit (RRR) needed to convince them to take on escalation of treatment. For the level of absolute risk of a flare during the next year needed to convince them to take extra treatment: at a 50\% risk level $78.7 \%$ would accept treatment escalation (table 4). A 25\% RRR was considered acceptable for treatment escalation by $43.3 \%$. For the level of absolute risk of an IBD-related hospitalisation over the next year needed to convince them to take extra treatment: at a 50\% risk level $79.4 \%$ would accept treatment escalation. A $25 \%$ RRR was considered acceptable for treatment escalation by $47.8 \%$. For the level of absolute risk of IBD-related surgery over the next 5 years needed to convince them to take extra treatment: at a $50 \%$ risk level $80.7 \%$ would accept treatment. A 25\% RRR was considered acceptable for treatment escalation by $50.2 \%$. For the level of absolute risk of a colorectal over the next 20 years needed to convince them to take extra treatment: at a $50 \%$ risk level $83.5 \%$ would accept treatment escalation. A 25\% RRR was considered acceptable for treatment escalation by $53.5 \%$.

There were no significant differences in the risk and benefits levels expected by patients with prior surgery compared with those without in respect of avoidance of hospitalisation, surgery or colorectal cancer.

\section{DISCUSSION}

This study examined patient views on a treat to target approach. Although medical opinion is shifting away from a symptom-based treatment approach to one aiming for at least mucosal healing with a treat to target strategy, ${ }^{1216}$ to date little attention has been paid to the patient perspective. ${ }^{17}$ Our study addresses an important gap in current evidence and demonstrates that, in a large cohort of patient not previously exposed to the concept of treat to target, $66.8 \%$ agreed to the approach in principle. Conversely, a third of patients did not agree with treat to target. This highlights an, as yet, unmet need to convince these patients of the benefits of treat to target.

Our study examined the views of patients in clinical remission, who are the most relevant, as this is the precise group of patients who would face further investigations, and possibly treatment escalation, under a treat to target approach. While patients with active disease face choices over treatments targets as well there are distinct differences between the two groups. First, patients with active disease are more likely adherent to treatment. Second, patients with active disease are mainly motivated by wanting to achieve symptom control a target already achieved for those patients in clinical remission. We chose Physician Global Assessment as the criterion for clinical remission as very few centres use formal disease activity scores such as Harvey-Bradshaw Index or Mayo Score in routine clinical encounters. The aim was to reflect real life clinical practice in identifying patients in clinical remission. To understand better which patients agree and which disagree with treat to target we examined several potentially associated demographic, diseaserelated, psychological, disease educational and treatment history-related factors. Interestingly, treatment with a second-line anti-TNF therapy was associated with a lower likelihood of accepting treat to target on univariate analysis only. This may relate to a history of previous treatment failures, and therefore represents patients with difficult to manage IBD. Patients in this situation are probably the least likely to benefit from a treat to target approach, as the benefits are expected to be higher in patients with shorter disease duration, and without previous treatment failures. ${ }^{12}$ Better current medication adherence was associated with an increased likelihood of accepting a treat to target approach, but median adherence levels in both accepting and nonaccepting patients were high.

Previous studies had examined patient views on accepting risk for maintenance of clinical remission only. ${ }^{27}$ In that scenario patients were willing to accept a $22.8 \%$ chance of a serious infection, and a $1.8 \%$ chance of a lymphoma, over a 5 -year time horizon in order to maintain clinical remission. ${ }^{27}$ We explored patients' views on different treatment targets including avoidance of flare, hospitalisation, surgery and colorectal cancer. There were surprisingly similar results for all four targets, suggesting that avoidance of any disease complication, rather than one complication in particular, is most relevant to patients. There is therefore a large unmet need for specific treat to target education for patients, in order to highlight the potential benefits of this approach. While two-thirds of patients indicated acceptance in our study, we cannot assume that this figures translates completely into 'real-world' acceptance, especially in light of nonadherence rates to treatments aimed at symptomatic remission of between $30 \%$ and $45 \% .{ }^{19}$ Patients seemed to be willing to accept significant risks in order to maintain disease control in a previous study of willingness to accept medication. ${ }^{27}$ Interestingly, that study found that symptomatic patients were less willing to accept risks than those in clinical remission. ${ }^{27}$ Lessons learnt from adherence research and studies reporting 
Table 4 Patient expectation on treatment targets

\begin{tabular}{|c|c|c|c|c|}
\hline Outcome to avoid & $\begin{array}{l}\text { Minimum level of risk } \\
\text { to agree to this target } \\
(\%)\end{array}$ & $\begin{array}{l}\text { Patient numbers } \\
\text { (accumulative } \\
\text { percentage) }\end{array}$ & $\begin{array}{l}\text { Minimum level of risk } \\
\text { reduction benefit to } \\
\text { agree to this target } \\
(\%)\end{array}$ & $\begin{array}{l}\text { Patient numbers } \\
\text { (accumulative } \\
\text { percentage) }\end{array}$ \\
\hline \multirow[t]{10}{*}{ Flare during next year } & 10 & $51(18.4)$ & 10 & $53(19.1)$ \\
\hline & 20 & $23(26.7)$ & 25 & $67(43.3)$ \\
\hline & 30 & $32(38.3)$ & 50 & $103(81.9)$ \\
\hline & 40 & $13(43.0)$ & 90 & $50(100.0)$ \\
\hline & 50 & $81(72.2)$ & & \\
\hline & 60 & $18(78.7)$ & & \\
\hline & 70 & $17(84.8)$ & & \\
\hline & 80 & $23(93.1)$ & & \\
\hline & 90 & $7(95.7)$ & & \\
\hline & 100 & $12(100.0)$ & & \\
\hline \multirow[t]{10}{*}{ Hospitalisation during next 1 year } & 10 & $85(29.6)$ & 10 & $81(31.1)$ \\
\hline & 20 & $33(41.1)$ & 25 & $62(47.8)$ \\
\hline & 30 & $34(53.0)$ & 50 & $95(79.6)$ \\
\hline & 40 & $10(56.4)$ & 90 & $61(100.0)$ \\
\hline & 50 & $54(75.3)$ & & \\
\hline & 60 & $12(79.4)$ & & \\
\hline & 70 & $14(84.2)$ & & \\
\hline & 80 & $15(89.5)$ & & \\
\hline & 90 & $6(91.6)$ & & \\
\hline & 100 & $24(100.0)$ & & \\
\hline \multirow[t]{10}{*}{ IBD-surgery during next 5 years } & 10 & $106(37.2)$ & 10 & $90(38.1)$ \\
\hline & 20 & $31(48.1)$ & 25 & $50(50.2)$ \\
\hline & 30 & $24(56.5)$ & 50 & $87(79.3)$ \\
\hline & 40 & $11(60.4)$ & 90 & $62(100.0)$ \\
\hline & 50 & $49(77.5)$ & & \\
\hline & 60 & $9(80.7)$ & & \\
\hline & 70 & $11(84.6)$ & & \\
\hline & 80 & $12(88.8)$ & & \\
\hline & 90 & $8(91.6)$ & & \\
\hline & 100 & $24(100.0)$ & & \\
\hline \multirow[t]{10}{*}{ Colorectal cancer during next 20 years } & 10 & $124(42.6)$ & 10 & $110(39.5)$ \\
\hline & 20 & $31(53.3)$ & 25 & $50(53.5)$ \\
\hline & 30 & $32(64.3)$ & 50 & $84(81.6)$ \\
\hline & 40 & $9(67.4)$ & 90 & $55(100.0)$ \\
\hline & 50 & $47(83.5)$ & & \\
\hline & 60 & $8(86.3)$ & & \\
\hline & 70 & $3(87.3)$ & & \\
\hline & 80 & $13(91.8)$ & & \\
\hline & 90 & $4(93.1)$ & & \\
\hline & 100 & $20(100.0)$ & & \\
\hline
\end{tabular}

patients' acceptance of risk, ${ }^{27}$ may form the basis for developing an educational intervention. Medication adherence is consistently associated with the belief in the need for medication and low concerns about potential side effects. ${ }^{202328}$ The key message for a treat to target intervention may therefore need to focus on highlighting the benefits of the approach, in order to demonstrate the need for treatment. ${ }^{1929}$
Patient's symptoms and objective control of inflammation often do not match, and up to $25 \%$ of patients with symptoms have no objective inflammation, while another quarter are asymptomatic, yet have detectable mucosal inflammation. ${ }^{8}$ While some studies suggest that patients with occult inflammation are at increased risk of disease complication a recent study from our centre found no increased risk of flare in those with 
occult inflammation. ${ }^{30}$ In our cohort we found a weak correlation with patient-reported disease state and FC for the current disease state. As we defined clinical remission as a period of 2 weeks prior to participation this likely reflects residual inflammation from recent flares.

The key strengths of our study are the large cohort of patients in clinical remission. For the cohort examined, treat to target is most relevant, as we only included patients in clinical remission. We deliberately chose conditions that reflect day-to-day practice, where treat to target would change treatment the most. A further strength is that the interviews were standardised and delivered by a single research nurse, thereby achieving consistency. There are, however, a number of limitations. First, the study was conducted in a single centre, and therefore may have been influenced by the treatment approach at this centre. Second, the study scenario was hypothetical, and therefore we can only make assumptions based on how the findings would translate into real-world clinical practice when proposing concrete treatments. Third, in order not to overload the scenario further we did not ask about treatment risks such as infective complications or lymphoma that were studied in previous work. ${ }^{27}$ Fourth, again in order not to overload the scenario further and to keep the complexity of the scenario low we did not suggest any specific changes to medical treatment (injection vs infusions vs oral medication) or the measures required for future assessment of the treatment target (colonoscopy vs calprotectin vs clinical outcomes). Fifth, we did not specifically ask patient why they gave their specific score on the acceptability of treat to target and can therefore not provide granular detail why patients chose not to accept the approach.

It is important to understand patient views on treat to target before attempting implementation. As we have demonstrated, $66 \%$ accept a treat to target approach, but a substantial minority do not. Patient education and counselling materials will therefore need to be developed to convince relevant patients of the importance of this strategy.

Contributors CS designed the study, analysed the data and wrote the draft manuscript. All authors contributed equally to data collection and interpretation of results. All other authors critically reviewed the manuscript.

Funding Abbvie provided funding for the study via an unrestricted research grant. AbbVie was not involved in the conduct and analysis of the study, nor the development or review of the manuscript with the authors. This manuscript reflects the opinions of the authors. The authors determined the final content, and all authors read and approved the final manuscript.

Competing interests CS has received unrestricted research grants from Warner Chilcott, Janssen and AbbVie, has provided consultancy to Warner Chilcott, Dr Falk, AbbVie, Takeda, Fresenius Kabi and Janssen, and had speaker arrangements with Warner Chilcott, Dr Falk, AbbVie, MSD, Pfizer and Takeda.

Patient consent for publication Not required.
Ethics approval The study protocol was approved following proportionate review by the NRES Committee East Midlands-Derby (reference: 15/EM/0412). All patients provided written informed consent.

Provenance and peer review Not commissioned; externally peer reviewed.

Data availability statement No data are available. The patient consent obtained does not cover data sharing.

Open access This is an open access article distributed in accordance with the Creative Commons Attribution Non Commercial (CC BY-NC 4.0) license, which permits others to distribute, remix, adapt, build upon this work noncommercially, and license their derivative works on different terms, provided the original work is properly cited, appropriate credit is given, any changes made indicated, and the use is noncommercial. See: http://creativecommons.org/licenses/by-nc/4. $0 /$.

\section{ORCID iDs}

Christian Selinger http://orcid.org/0000-0003-2022-5859

John Kane http://orcid.org/0000-0003-1066-2115

Alexander Charles Ford http://orcid.org/0000-0001-6371-4359

\section{REFERENCES}

$1 \mathrm{Kim} \mathrm{DH}$, Cheon JH. Pathogenesis of inflammatory bowel disease and recent advances in biologic therapies. Immune Netw 2017;17:25-40.

2 Lenti MV, Levison S, Eliadou E, et al. A real-world, long-term experience on effectiveness and safety of vedolizumab in adult patients with inflammatory bowel disease: the cross Pennine study. Dig Liver Dis 2018;50:1299-304.

3 Sandborn WJ, Su C, Sands BE, et al. Tofacitinib as induction and maintenance therapy for ulcerative colitis. N Engl J Med 2017;376:1723-36.

4 NICE. Infliximab, adalimumab and golimumab for treating moderately to severely active ulcerative colitis after the failure of conventional therapy: Technology appraisal guidance [TA329]. London: Excellence NIfHaC, 2015.

5 Feagan BG, Sandborn WJ, Gasink C, et al. Ustekinumab as Induction and Maintenance Therapy for Crohn's Disease. N Engl J Med 2016;375:1946-60.

6 Mowat C, Cole A, Windsor A, et al. Guidelines for the management of inflammatory bowel disease in adults. Gut 2011;60:571-607.

7 Westwood N, Travis SPL. Review article: what do patients with inflammatory bowel disease want for their clinical management? Aliment Pharmacol Ther 2008;27:1-8.

8 Gracie DJ, Williams CJM, Sood R, et al. Poor correlation between clinical disease activity and mucosal inflammation, and the role of psychological comorbidity, in inflammatory bowel disease. Am J Gastroenterol 2016;111:541-51.

9 Mooiweer E, Severs M, Schipper MEI, et al. Low fecal calprotectin predicts sustained clinical remission in inflammatory bowel disease patients: a plea for deep remission. J Crohns Colitis 2015;9:50-5.

10 Orlando A, Guglielmi FW, Cottone M, et al. Clinical implications of mucosal healing in the management of patients with inflammatory bowel disease. Dig Liver Dis 2013;45:98691.

11 Colombel J-F, Panaccione R, Bossuyt P, et al. Effect of tight control management on Crohn's disease (calm): a multicentre, randomised, controlled phase 3 trial. Lancet 2018;390:2779_ 89.

12 Sandborn WJ, Hanauer S, Van Assche G, et al. Treating beyond symptoms with a view to improving patient outcomes in inflammatory bowel diseases. J Crohns Colitis 2014;8:927-35.

13 Barreiro-de Acosta M, Vallejo N, de la Iglesia D, et al. Evaluation of the risk of relapse in ulcerative colitis according to the degree of mucosal healing (Mayo 0 vs 1 ): a longitudinal cohort study. ECCOJC 2016;10:13-19. 
14 Bryant RV, Burger DC, Delo J, et al. Beyond endoscopic mucosal healing in UC: histological remission better predicts corticosteroid use and hospitalisation over 6 years of followup. Gut 2016;65:408-14.

15 Rogler G. Top-Down or step-up treatment in Crohn's disease? Dig Dis 2013;31:83-90.

16 Peyrin-Biroulet L, Sandborn W, Sands BE, et al. Selecting therapeutic targets in inflammatory bowel disease (STRIDE): determining therapeutic goals for Treat-to-Target. Am J Gastroenterol 2015;110:1324-38.

17 Ungaro R, Colombel J-F, Lissoos T, et al. A Treat-to-Target update in ulcerative colitis: a systematic review. Am J Gastroenterol 2019;114:874-83.

18 De Cruz P, Kamm MA, Hamilton AL, et al. Crohn's disease management after intestinal resection: a randomised trial. Lancet 2015;385:1406-17.

19 Lenti MV, Selinger CP. Medication non-adherence in adult patients affected by inflammatory bowel disease: a critical review and update of the determining factors, consequences and possible interventions. Expert Rev Gastroenterol Hepatol 2017;22:1-12.

20 Selinger CP, Eaden J, Jones DB, et al. Modifiable factors associated with nonadherence to maintenance medication for inflammatory bowel disease. Inflamm Bowel Dis 2013;19:2199-206.

21 Zigmond AS, Snaith RP. The hospital anxiety and depression scale. Acta Psychiatr Scand 1983;67:361-70.

22 Irvine EJ, Zhou Q, Thompson AK. The short inflammatory bowel disease questionnaire: a quality of life instrument for community physicians managing inflammatory bowel disease. CCRPT Investigators. Canadian Crohn's relapse prevention trial. Am J Gastroenterol 1996;91:1571-8.

23 Horne R, Parham R, Driscoll R, et al. Patients' attitudes to medicines and adherence to maintenance treatment in inflammatory bowel disease. Inflamm Bowel Dis 2009;15:83744.

24 Selinger CP, Ochieng AO, George V, et al. The accuracy of adherence self-report scales in patients on thiopurines for inflammatory bowel disease: a comparison with drug metabolite levels and medication possession ratios. Inflamm Bowel Dis 2019;25:919-24.

25 Keegan D, McDermott E, Byrne K, et al. Development, validation and clinical assessment of a short questionnaire to assess disease-related knowledge in inflammatory bowel disease patients. Scand J Gastroenterol 2013;48:183-8.

26 Jackson CA, Clatworthy J, Robinson A, et al. Factors associated with non-adherence to oral medication for inflammatory bowel disease: a systematic review. Am J Gastroenterol 2010;105:525-39.

27 Bewtra M, Fairchild AO, Gilroy E, et al. Inflammatory bowel disease patients' willingness to accept medication risk to avoid future disease relapse. Am J Gastroenterol 2015;110:1675-81.

28 Moshkovska T, Stone MA, Clatworthy J, et al. An investigation of medication adherence to 5 -aminosalicylic acid therapy in patients with ulcerative colitis, using self-report and urinary drug excretion measurements. Aliment Pharmacol Ther 2009;30:1118-27.

29 Selinger CP, Kinjo Y, Jones DB, et al. Conveying medication benefits to ulcerative colitis patients and effects on patient attitudes regarding thresholds for adherence. J Crohns Colitis 2013;7:e312-7.

30 Gracie DJ, Williams CJM, Sood R, et al. Negative effects on psychological health and quality of life of genuine irritable bowel Syndrome-type symptoms in patients with inflammatory bowel disease. Clin Gastroenterol Hepatol 2017;15:376-84. 